УДК 332.122

\title{
А. Н. Герасимов
}

ФГБОУ ВО «Ставропольский государственный аграрный университет», Ставрополь, e-mail: gerasimov_77_77@mail.ru

\section{О. П. Григорьева}

ФГБОУ ВО «Ставропольский государственный аграрный университет», Ставрополь, e-mail: ksuta_stav@mail.ru

\section{Ю. С. Скрипниченко}

ФГБОУ ВО «Ставропольский государственный аграрный университет», Ставрополь, e-mail: maxim-84@list.ru

\section{СТАТИСТИЧЕСКАЯ ОЦЕНКА РЕЗУЛЬТАТОВ ИМПОРТОЗАМЕЩЕНИЯ СЕЛЬСКОХОЗЯЙСТВЕННОЙ ПРОДУКЦИИ В РЕГИОНЕ}

Ключевые слова: сельскохозяйственное производство; структура производства сельскохозяйственной продукции региона; импортозамещающая продукция сельского хозяйства.

В статье проведен ретроспективный динамический анализ предпринимательских структур в сфере аграрного производства в Ставропольском крае. Было выявлено снижение общего количества предпринимательских структур в регионе за последние 5 лет на 11,5\%. Сельскохозяйственные организации на конец 2018 г. производят существенную долю такой сельскохозяйственной продукции, как зерновые культуры $(82,5 \%)$, семена подсолнечника $(87,0 \%)$, мясо всех видов $(76,1 \%)$. В то же время, их доля в производстве других сельскохозяйственных продуктов незначительна. На основании результатов ретроспективного анализа сельскохозяйственных организаций были выявлены направления импортозамещающего производства: овощей открытого грунта в растениеводстве и молока в животноводстве.

\section{A. N. Gerasimov}

Stavropol state agrarian University, Stavropol, e-mail: gerasimov_77_77@mail.ru

\section{O. P. Grigoryeva}

Stavropol state agrarian University, Stavropol, e-mail: ksuta_stav@mail.ru

\section{Yu. S. Skripnichenko}

Stavropol state agrarian University, Stavropol, e-mail: maxim-84@list.ru

\section{STATISTICAL ASSESSMENT OF AGRICULTURAL IMPORT SUBSTITUTION RESULTS IN THE REGION}

Keywords: Agricultural production; Agricultural production structure of the region; Import substituting agricultural products.

In the article, a retrospective dynamic analysis of entrepreneurial structures in the field of agricultural production in the Stavropol region was carried out. The total number of business structures in the region has decreased by $11.5 \%$ over the past 5 years. Agricultural organizations at the end of 2018 produce a significant share of agricultural products such as cereals $(82.5 \%)$, sunflower seeds $(87.0 \%)$, meat of all kinds $(76.1 \%)$. At the same time, their share in the production of other agricultural products is insignificant. On the basis of the results of retrospective analysis of agricultural organizations, the directions of import substitution production were revealed: open soil vegetables in crop production and milk in livestock production.

\section{Введение}

Ставропольский край является одним из важнейших сельскохозяйственных регионов России. Богатые почвы и хорошие климатические условия создают широкие возможности для развития всех отраслей сельскохозяйственного производства.

\section{Цель исследования}

Целью исследования является анализ производственно-хозяйственной деятельности аграрно-ориентированных предпринимательских структур в области производства импортозамещающей сельскохозяйственной продукции в регионе. 
Материалы и методы исследования

Объектом исследования являются предпринимательские структуры в сфере сельскохозяйственного производства Ставропольского края. Методологическая основа исследования представлена объективными принципами научного познания, моделирования, системного подхода, группировки данных, использования положений экономической теории, бухгалтерского учета, статистики и экономического анализа.

Объемы производства сельскохозяйственной продукции в целом по России и в Ставропольском крае приведены в таблице 1.

Таким образом, в Ставропольском крае производится в среднем за период 2014-2018 гг. 8,2\% валового производства зерна страны, $4,7 \%$ сахарной свёклы, $4,9 \%$ семян подсолнечника и $2,9 \%$ овощей. Что касается продукции животноводства, то доля производства мяса всех видов в среднем составляет 4,3\%, молока $2,2 \%$, яиц $1,6 \%$. В целом, в регионе возделывается более 50 различных видов сельскохозяйственных культур, уделяется большое внимание отрасли животноводства и птицеводства.

Необходимо отметить, что из года в год увеличивается потребность населения в сельскохозяйственной продукции, что и обуславливает увеличение объемов ее производства. Кроме того, в настоящее время государственные программы направлены на развитие и поддержку отечественного производителя, что также оказывает положительный результат на деятельность сельхозпроизводителей.

В современных условиях немаловажная роль отводится увеличению объемов производства импортозамещающей продукции в целях насыщения регионального рынка продукцией, способной заменить ранее импортируемую продукцию. В первую очередь это овощи и молоко.

\section{Таблица 1}

Производство сельскохозяйственной продукции в Российской Федерации и Ставропольском крае

\begin{tabular}{|c|c|c|c|c|c|c|}
\hline $\begin{array}{c}\text { Объем производства } \\
\text { продукции, тысяч тонн }\end{array}$ & 2014 & 2015 & 2016 & 2017 & 2018 & $\begin{array}{c}\text { Темп } \\
\text { роста, } \%\end{array}$ \\
\hline \multicolumn{7}{|c|}{ Растениеводство } \\
\hline \multicolumn{7}{|l|}{ Зерновые культуры: } \\
\hline Россия & 92400 & 105300 & 104800 & 120700 & 134100 & 145,1 \\
\hline Ставропольский край & 7118 & 8741 & 9105 & 10459 & 10234 & 143,8 \\
\hline \multicolumn{7}{|l|}{ Подсолнечник: } \\
\hline Россия & 10600 & 9000 & 9300 & 11000 & 9600 & 90,6 \\
\hline Ставропольский край & 448 & 395 & 405 & 553 & 620 & 138,4 \\
\hline \multicolumn{7}{|l|}{ Сахарная свекла: } \\
\hline Россия & 39300 & 33500 & 39000 & 51400 & 48200 & 122,6 \\
\hline Ставропольский край & 1497 & 1812 & 1768 & 2618 & 2159 & 144,2 \\
\hline \multicolumn{7}{|l|}{ Овощи: } \\
\hline Россия & 14700 & 15500 & 16100 & 16300 & 16300 & 110,9 \\
\hline Ставропольский край & 508 & 440 & 446 & 420 & 427 & 84,1 \\
\hline \multicolumn{7}{|c|}{ Животноводство } \\
\hline \multicolumn{7}{|l|}{ Скот и птица на убой: } \\
\hline Россия & 8544 & 9070 & 9565 & 9931 & 14600 & 170,9 \\
\hline Ставропольский край & 374 & 387 & 419 & 487 & 485 & 129,7 \\
\hline \multicolumn{7}{|l|}{ Молоко: } \\
\hline Россия & 30500 & 30800 & 30800 & 30700 & 31100 & 102,0 \\
\hline Ставропольский край & 681 & 687 & 687 & 682 & 632 & 92,8 \\
\hline \multicolumn{7}{|l|}{ Яйца, млн штук: } \\
\hline Россия & 41300 & 41900 & 42600 & 43500 & 44800 & 108,5 \\
\hline Ставропольский край & 796 & 708 & 677 & 655 & 648 & 81,4 \\
\hline
\end{tabular}


В то же время, динамика производства этих видов продукции отрицательная. Например, производство зерновых культур увеличилось в целом по стране на $45,1 \%$ в 2018 г. по сравнению с 2014 г. (в Ставропольском крае соответственно увеличилось на 43,8\%). Производство подсолнечника в РФ снизилось на 9,4\%, в то же время в Ставропольском крае увеличилось на $38,4 \%$ и составило в 2018 г. 620 тысяч тонн. Производство сахарной свёклы в России увеличилось на 22,6\% по сравнению с 2014 г., а в Ставропольском крае на $44,2 \%$. Производство овощей открытого грунта в стране увеличилось на 10,9\%, при этом в регионе снизилось на 15,9\%.

Таким образом, динамика физического объема продукции растениеводческой подотрасли Ставропольского края не всегда совпадает с общероссийскими показателями. А что касается производства овощей открытого грунта, относящихся к импортозамещающей продукции, то имеет место существенное снижение объема их производства.

В подотрасли животноводства по России наблюдается общая положительная динамика производства мяса всех видов - в 2018 г. наблюдается увеличение объемов производства в 1,7 раза по сравнению с 2014 г. При этом темпы роста производства мяса в Ставропольском крае значительно ниже - прирост составил лишь 29,7\% за последние 5 лет. Производство молока в стране увеличилось незначительно - на 2,0\% с 2014 года. При этом в Ставропольском крае произошло снижение на 7,2\%, а об- щий объем производства составил 632 тысячи тонн. Производство яиц увеличилось в России в целом на $8,5 \%$, при этом в Ставропольском крае снизилось на $18,6 \%$.

Таким образом, производство молока в Ставропольском крае как основной импортозамещающей продукции животноводческой подотрасли сельскохозяйственного производства требует исследования факторов, оказывающих влияние на подобные темпы снижения объемов производства.

Происходящие реформы в экономике нашей страны и агропромышленном комплексе внесли существенные корректировки в организационно-правовые формы и формы собственности сельскохозяйственных организаций Ставропольского края.

По состоянию на конец 2018 г. в сельском хозяйстве Ставропольского края насчитывается 521 предпринимательская структура. В целом, количество сельскохозяйственных организаций в крае снизилось за последние 5 лет на 11,5\%.

При этом количество открытых (публичных) акционерных обществ увеличилось на $13,6 \%$ и составило 25 единиц в 2018 г. по сравнению с 22 - в 2013 г. Количество закрытых акционерных обществ снизилось на 37,0\%. Количество обществ с ограниченной ответственностью осталось почти неизменным. Сельскохозяйственные кооперативы и крестьянские (фермерские) хозяйства снизили численность примерно одинаково - более чем на четверть.

\section{Таблица 2}

Изменение состава субъектов аграрного бизнеса Ставропольского края в разрезе организационно-правовых форм

\begin{tabular}{|l|c|c|c|c|c|c|c|}
\hline \multicolumn{1}{|c|}{ Показатель } & 2013 & 2014 & 2015 & 2016 & 2017 & 2018 & $\begin{array}{c}2018 \text { г. в\% } \\
\text { к 2013 г. }\end{array}$ \\
\hline Бизнес-структуры АПК, всего & 589 & 599 & 582 & 573 & 538 & 521 & 88,5 \\
\hline $\begin{array}{l}\text { в том числе: } \\
\text { государственные предприятия }\end{array}$ & 5 & 5 & 5 & 4 & 4 & 3 & 88,5 \\
\hline открытые (публичные) акционерные общества & 22 & 20 & 19 & 25 & 25 & 25 & 113,6 \\
\hline закрытые акционерные общества & 54 & 54 & 53 & 43 & 40 & 34 & 63,0 \\
\hline общества с ограниченной ответственностью & 302 & 309 & 306 & 318 & 305 & 303 & 100,3 \\
\hline сельскохозяйственные производственные кооперативы & 131 & 123 & 116 & 108 & 100 & 96 & 73,3 \\
\hline крестьянские (фермерские) хозяйства & 70 & 79 & 72 & 66 & 58 & 52 & 74,3 \\
\hline прочие & 5 & 9 & 11 & 9 & 9 & 8 & 160,0 \\
\hline
\end{tabular}




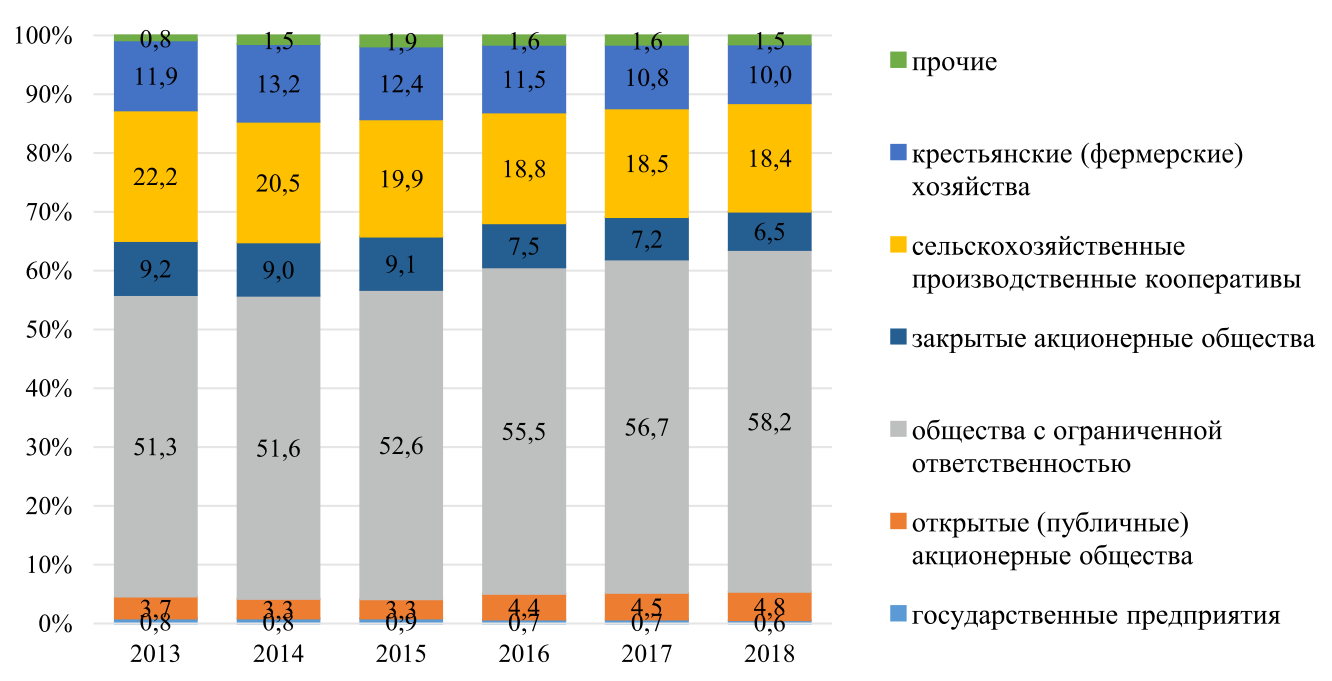

Рис. 1. Изменение структуры субъектов аграрного бизнеса Ставропольского края за 2013-2018 г2. в разрезе организационно-правовых форм

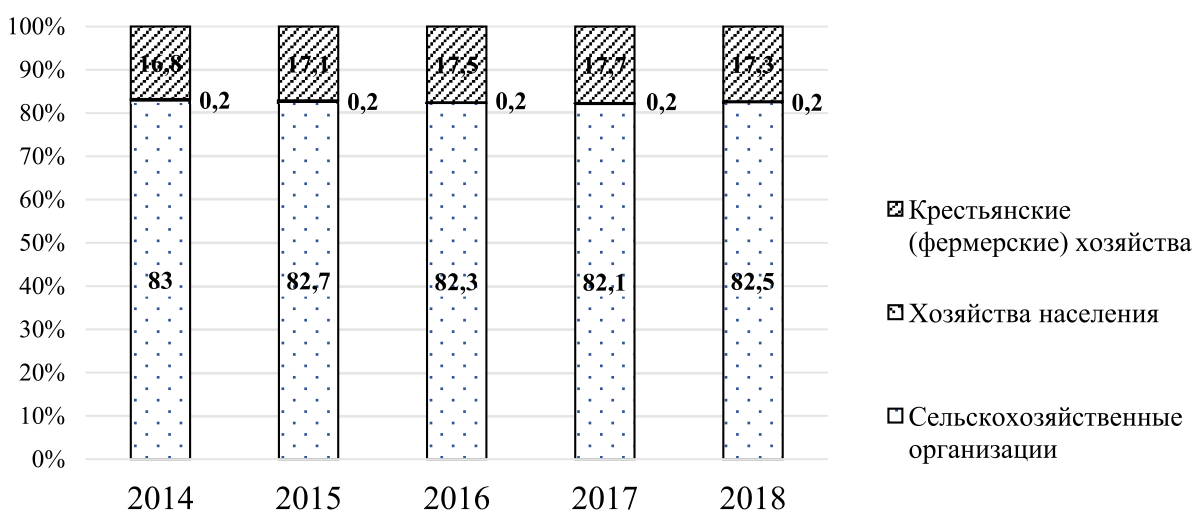

Рис. 2. Структура производства зерновых культур в разрезе категорий хозяйств

На рисунке 1 представлена структура субъектов аграрного бизнеса в динамике за 2013-2018 гг.

За последние годы произошло снижение доли сельскохозяйственных производственных кооперативов с 22,2\% до $18,4 \%$, закрытых акционерных обществ - с 9,2\% до 6,5\%, крестьянских (фермерских) хозяйств - с 11,9 до 10\%. Доля открытых акционерных обществ, государственных предприятий и прочих форм остается на протяжении всего периода исследования незначительной.

Обращает на себя внимание увеличение доли обществ с ограниченной ответственностью с 51,3\% в 2013 г. до 58,2\% в 2018 г.
Далее определим доли сельскохозяйственных предпринимательских структур в общем объеме производства продукции сельского хозяйства в разрезе категорий хозяйств.

На рисунке 2 представлена структура производства зерновых культур в разрезе категорий хозяйств.

Таким образом, более $80 \%$ общего объема производства зерновых культур в Ставропольском крае приходится на предпринимательские структуры сельскохозяйственного производства. За период с 2014 по 2018 г. их доля снизилась лишь на $0,5 \%$. В то же время доля крестьянских (фермерских) хозяйств в производстве зерновых культур 
увеличилась с 16,8\% в 2014 г. до 17,3\% в 2018 г. Доля хозяйств населения в производстве этого вида сельскохозяйственной продукции традиционно невелика и составляет $0,2 \%$.

Следовательно, подавляющую долю зерна в регионе производят сельскохозяйственные бизнес-структуры. Поэтому оценка производства зерновых культур сельскохозяйственными организациями будет являться основой для изучения всего рынка зерна в целом по краю.

На рисунке 3 представлена структура производства семян подсолнечника в Ставропольском крае в разрезе категорий хозяйств.

Таким образом, до $87 \%$ общего объема производства подсолнечника в Ставропольском крае приходится на предпринимательские структуры сельскохозяйственного производства. За период с 2014 по 2018 г. их доля снизилась лишь на $0,6 \%$ и составила $87,0 \%$.

При этом доля крестьянских (фермерских) хозяйств в производстве подсолнечника увеличилась с 12,2\% в 2014 г. до $12,8 \%$ в 2018 г. Доля хозяйств населения в производстве этого вида сельскохозяйственной продукции увеличилась незначительно и составила 0,3\% от общего объема производства.

Следовательно, подавляющую долю семян подсолнечника в регионе производят сельскохозяйственные бизнесструктуры. Поэтому оценка объемов производства подсолнечника сельскохозяйственными организациями будет являться основой для изучения всего рынка этой продукции в целом по Ставропольскому краю.

На рисунке 4 представлена структура производства картофеля в Ставропольском крае в разрезе категорий хозяйств.

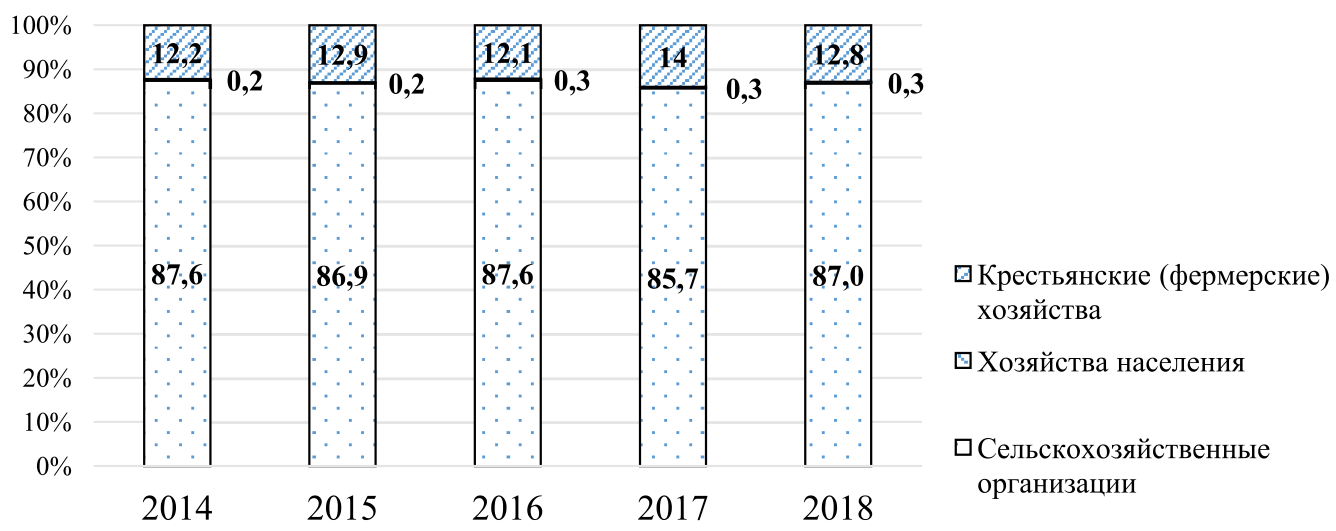

Рис. 3. Структура производства подсолнечника в разрезе категорий хозяйств

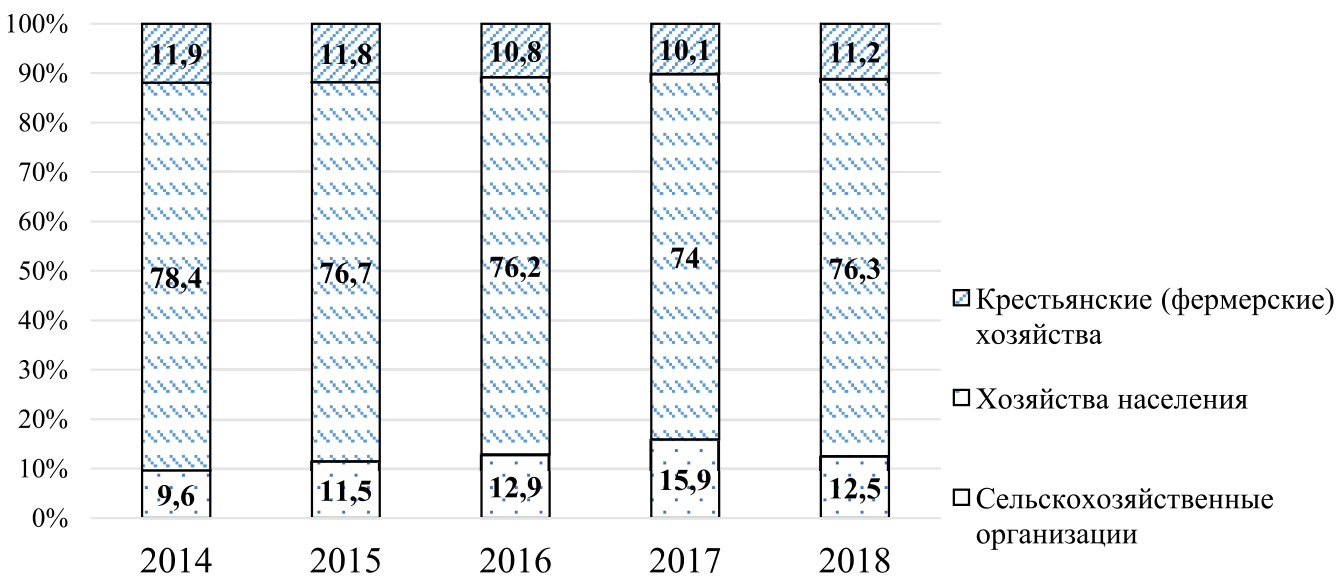

Рис. 4. Структура производства картофеля в разрезе категорий хозяйств 
Таким образом, доля сельскохозяйственных организаций в общем объеме производства картофеля невелика: она увеличилась с 9,6\% в 2014 г. до $12,5 \%$ в 2018 г.

При этом доля хозяйств населения в производстве подсолнечника снизилась с 78,4\% в 2014 г. до 76,3\% в 2018 г. Доля крестьянских (фермерских) в производстве этого вида сельскохозяйственной продукции уменьшилась с 11,9\% в 2014 г. до 11,2\% в 2018 г. Следовательно, подавляющую долю картофеля в регионе производят крестьянские (фермерские) хозяйства.

То есть для оценки перспектив производства этого вида сельскохозяйственной продукции следует большее внимание уделять исследованию домашних хозяйств.

На рисунке 5 представлена структура производства овощей открытого грунта в Ставропольском крае в разрезе категорий хозяйств.

Таким образом, сельскохозяйственные организации производят в среднем четвертую часть овощей открытого грунта в Ставропольском крае. При этом в течение 2014-2018 гг. их доля в производстве этой продукции остается практически неизменной.

Хозяйства населения производят большую часть овощей открытого грунта в Ставропольском крае. В 2014 г. их доля составляла $31,7 \%$, а в 2018 г. составила уже 45,4\%, приближаясь к отметке в $50 \%$ общего физического объема производства овощей.

Доля крестьянских (фермерских) хозяйств в производстве овощей превыша- ет долю сельскохозяйственных организаций. В 2014 г. она составляла 42,5\%, а в 2018 г. снизилась до 30,1\%.

Следовательно, подавляющую долю овощей открытого грунта в регионе производят хозяйства населения.

На рисунке 6 представлена структура производства мяса всех видов в Ставропольском крае в разрезе категорий хозяйств.

Структура производства этого вида животноводческой продукции заметно отличается от структуры продукции растениеводства. Так, на сельскохозяйственные организации приходится от $62 \%$ (в 2014 г.) до 76,1\% (в 2018 г.) всего физического объема производства мяса всех видов.

Доля хозяйств населения снизилась с $33,4 \%$ в 2014 г. до $19,6 \%$ в 2018 г. в общем объеме производства мяса.

В то же время, доля хозяйств населения практически оставалась неизменной на уровне выше 4\% и в 2018 г. составила $4,3 \%$.

Исследование структуры производства мяса всех видов в разрезе категорий хозяйств позволяет сделать вывод, что для выявления закономерностей изменения производства данного вида продукции достаточно изучить только деятельность субъектов агробизнеса.

На рисунке 7 представлена структура производства молока в Ставропольском крае в разрезе категорий хозяйств.

Как видно из рисунка, доля сельскохозяйственных организаций в производстве молока незначительна: от 20,4\% в 2014 г. до $21,3 \%$ - в 2018 г.

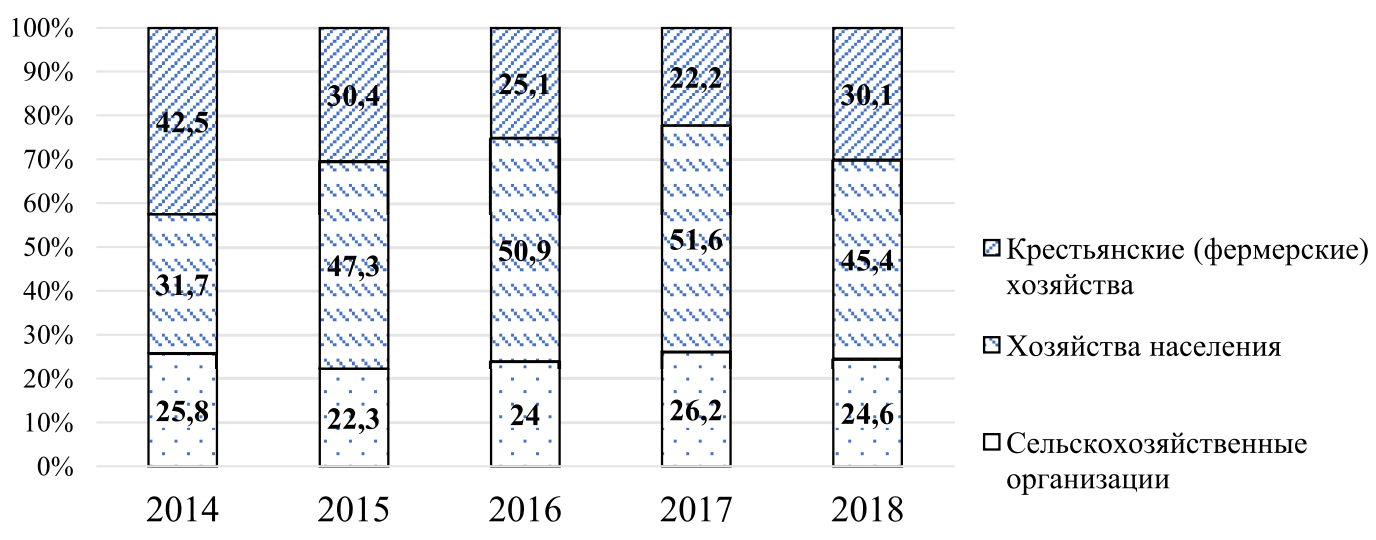

Рис. 5. Структура производства овощей открытого грунта в разрезе категорий хозяйств 


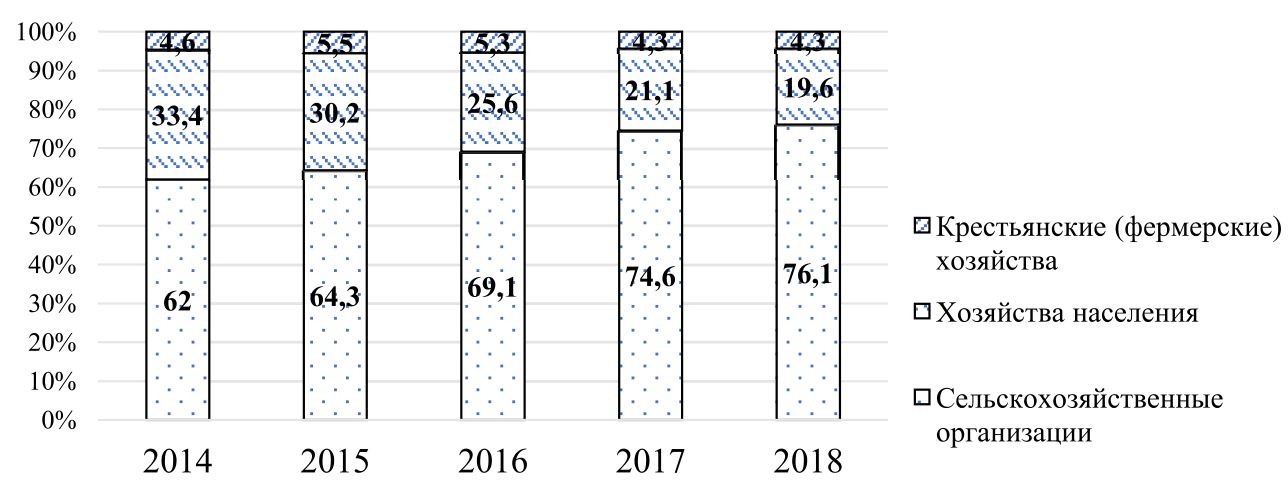

Рис. 6. Структура производства мяса всех видов в разрезе категорий хозяйств

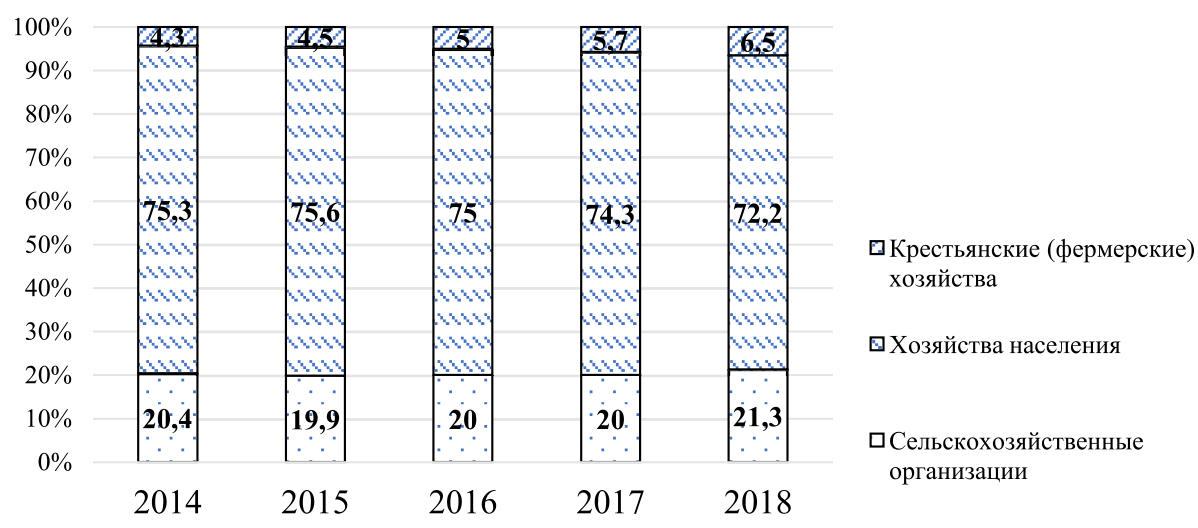

Рис. 7. Структура производства молока в разрезе категорий хозяйств

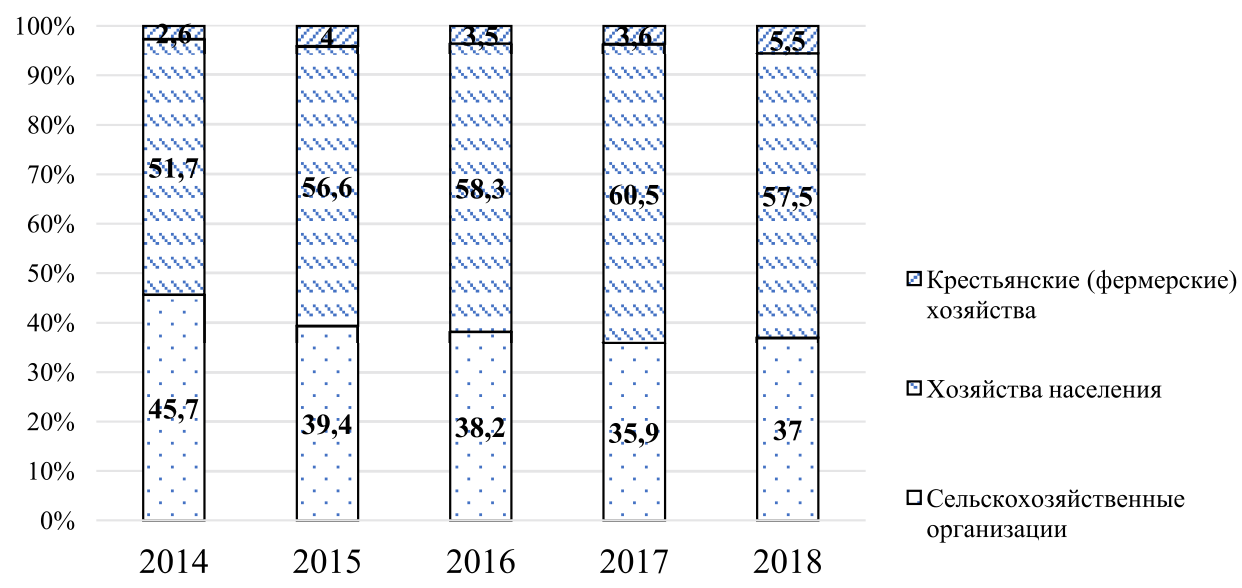

Рис. 8. Структура производства яиц в разрезе категорий хозяйств

Ведущая роль в производстве молока в Ставропольском крае принадлежит хозяйствам населения. При этом их доля незначительно снизилась с 75,3\% в 2014 г. до $72,2 \%$ в 2018 г.

Доля крестьянских (фермерских) хозяйств при этом увеличилась с 4,3\% до $6,5 \%$ в 2018 г.
На рисунке 8 представлена структура производства яиц в Ставропольском крае в разрезе категорий хозяйств.

В структуре производства яиц доля сельскохозяйственных организаций снизилась с 45,7\% в 2014 г. до $37 \%$ в 2018 г.

На первом месте по производству яиц в Ставропольском крае находятся 
хозяйства населения: их доля составляет больше половины и увеличилась с 51,7\% в 2014 г. до 57,5\% в 2018 г.

Крестьянские (фермерские) хозяйства производят от 2,6\% яиц в 2014 г. до 5,5\% - в 2018 г.

\section{Выводы}

Таким образом, можно сделать вывод, что пропорции производства различных видов сельскохозяйственной продукции в Ставропольском крае неодинаковы. Более того, они подвержены изменениям с течением времени. Поэтому исследование производственно-хозяйственной деятельности предпринимательских структур в сельском хозяйстве, на наш взгляд, следует проводить дифференцированно, в зависимости от вида сельскохозяйственной продукции.

На наш взгляд, особого внимания заслуживает производство сельскохозяйственными организациями импортозамещающей продукции, а именно овощей в растениеводстве и молока - в животноводстве. Следует отметить, что доля сельскохозяйственных организаций в производстве этих видов продукции мала. Поэтому увеличение объемов производства с помощью привлечения государственной поддержки может привести к устойчивому росту сельскохозяйственного производства региона и решить проблему импортозамещения востребованной населением сельскохозяйственной продукции.

\section{Библиографический список}

1. Галазова С.С. Финансовая стабильность и экономическое развитие / С.С Галазова // Финансовые исследования. 2017. № 4 (57). С. 23-30.

2. Киселева Н.Н. Промышленная политика регионов Северо-Кавказского федерального округа в координатах геоэкономических вызовов / Н.Н. Киселева, А.А. Орлянская, Н.В. Боровикова // Вестник Волгоградского государственного университета. Серия 3: Экономика. Экология. 2017. T. 19. № 3. С. 155-163.

3. Рокотянская В.В. Интегральная оценка уровня инновационного потенциала регионов России / В.В. Рокотянская // Экономика и предпринимательство. 2017. № 9-2 (86-2). С. 768-771.

4. Рокотянская В.В. Организационно-экономические институциональные инструменты интеграции аграрного сектора в систему ВТО / В.В. Рокотянская // Экономика, статистика и информатика. Вестник УМО. 2012. № 3-2. С. 254-258.

5. Татуев А.А. Проблемы формирования цепочек добавленной стоимости биопродуктов в экономике природопользования / А.Б. Нагоев, А.А. Татуев, С.А. Скляренко, В.И. Шаров // Фундаментальные исследования. 2015. № 11-1. С. 174-178.

6. Трухачёв В.И. Концептуальные подходы к разработке и реализации стратегии развития регионального АПК / В.И. Трухачёв, Н.В. Банникова // Экономика сельскохозяйственных и перерабатывающих предприятий. 2010. № 3. С. 28-30.

7. Тяглов С.Г. Современные подходы к решению проблем модернизации региональной экономики / С.Г. Тяглов // Национальные интересы: приоритеты и безопасность. 2011. № 36. С. 26-29.

8. Хайруллина О.И. Международные показатели оценки уровня государственной поддержки в контексте ВТО / О.И. Хайруллина // Международная экономика. 2012. № 7. С. 53-63.

9. Хайруллина О.И. Методика оценки эффективности государственной поддержки / О.И. Хайруллина // Известия Оренбургского государственного аграрного университета. 2012. Т. 5. № 37-1. C. 200-204.

10. Яркова Т.М. Российский экспорт и импорт продовольствия: состояние и перспективы / Т.М. Яркова // Т.М. Аграрный вестник Урала. 2011. № 3. С. 133-134. 